\title{
Utility of endoscopic ultrasound-guided fine-needle aspiration in pancreatic cancer patients who failed to obtain a pathological diagnosis in surgical exploration
}

\author{
Meng-Jiang He", Tian-Yin Chen", Xin-Yang Liu, Xiao-Yue Xu, Ping-Hong Zhou, Yi-Qun Zhang \\ Endoscopy Center and Endoscopy Research Institute, Zhongshan Hospital, Fudan University, Shanghai, China \\ Contributions: (I) Conception and design: MJ He, YQ Zhang; (II) Administrative support: PH Zhou, YQ Zhang; (III) Provision of study materials or \\ patients: MJ He, TY Chen; (IV) Collection and assembly of data: TY Chen, XY Xu; (V) Data analysis and interpretation: XY Liu; (VI) Manuscript \\ writing: All authors; (VII) Final approval of manuscript: All authors. \\ "These authors contributed equally to this work. \\ Correspondence to: Ping-Hong Zhou, MD, PhD, FASGE; Yi-Qun Zhang, MD, PhD. Endoscopy Center and Endoscopy Research Institute, Zhongshan \\ Hospital, Fudan University, 180 Fenglin Road, Shanghai 200032, China. Email: zhou.pinghong@zs-hospital.sh.cn; zhang.yiqun@zs-hospital.sh.cn.
}

\begin{abstract}
Background Endoscopic ultrasound-guided fine-needle aspiration (EUS-FNA) allows for the analysis of diagnostic tissue specimens from various regions. For pancreatic tumors, especially un-resectable ones, how to obtain pathological confirmation is important for determining sub-sequent treatment. The purpose of this study is to investigate the clinical utility of EUS-FNA in patients who failed to obtain a pathological diagnosis in surgical exploration.
\end{abstract}

Methods: Patients who underwent EUS-FNA due to unsuccessful biopsy in surgical exploration in our center were retrospectively reviewed. All of the patients were diagnosed with resectable disease before surgery but were found to be unresectable during surgery. The positive rate of pathological diagnosis of EUS-FNA was analyzed.

Results: A total of 11 patients were included in this study, among which 8 were males and 3 were females. The median age of the patients was 55 years (range, 48 to 73 years). The median lesion size was $34 \mathrm{~mm}$ (range, 25 to $44 \mathrm{~mm}$ ). The median number of needle passes was 3 (range, 1 to 3). Two patients underwent biliary stent implantation while 3 patients underwent gastrojejunostomy before EUS-FNA. The technical success rate of EUS-FNA was $100 \%$ (11/11); 10 (90.9\%, 10/11) samples were positive and 1 was negative (being inadequate).

Conclusions: Intraoperative biopsy is the first choice diagnostic modality for unresectable pancreatic neoplasms. However, for patients who fail to obtain a pathological diagnosis in surgical exploration, EUSFNA is still worth an attempt.

Keywords: Endoscopic ultrasound-guided fine-needle aspiration (EUS-FNA); unresectable pancreatic cancer; surgical exploration

Submitted Dec 16, 2021. Accepted for publication Feb 11, 2022.

doi: $10.21037 / g s-21-913$

View this article at: https://dx.doi.org/10.21037/gs-21-913

\section{Introduction}

Pancreatic cancer is an aggressive malignancy with a poor prognosis, with an overall 5-year survival rate of $2-9 \%$ (1). Surgery remains the only potentially curative treatment for pancreatic cancer, but most patients are diagnosed at an advanced stage and only $15 \%$ to $20 \%$ of patients are eligible for this procedure (2). Pancreatic cancer resectability is determined primarily by the degree of tumor-vascular contact, based on a routine pancreas CT. Although in recent decades emerging imaging 
techniques have improved the predictive accuracy of resectability, unresectable lesions may still be encountered at surgery. Intraoperative pancreas biopsy or resection of suspicious metastatic lymph nodes is most widely used for pathological confirmation in these patients $(3,4)$, though sometimes these techniques still cannot obtain pathological confirmation, which is important for the subsequent therapeutic regimen. Whether the utility of endoscopic ultrasound-guided fine-needle aspiration (EUS-FNA) still benefit these patients who fail to obtain a pathological diagnosis in surgical exploration has not yet been reported. Anatomy change and tissue swelling sometimes happened after surgical exploration, whether these factors impact the utility of EUS-FNA in these patients remained unclear. The purpose of this study is to investigate the clinical utility of EUS-FNA in patients that fail to obtain a pathological diagnosis in surgical exploration. We present the following article in accordance with the STROBE reporting checklist (available at https://gs.amegroups.com/ article/view/10.21037/gs-21-913/rc).

\section{Methods}

\section{Patients}

This is a single-center retrospective cohort study investigating the utility of EUS-FNA in patients that fail to obtain a pathological diagnosis in surgical exploration. With the approval of the institutional ethics board of Zhongshan Hospital (No. B2021-213R), all patients who underwent EUS-FNA for pancreatic disease from July 2017 to June 2020 at Zhongshan Hospital, Fudan University were screened retrospectively. The inclusion criteria were as follows: (I) patients were stratified as resectable before surgery but were found to be unresectable at surgery; (II) intraoperative biopsy and/or resection of suspicious metastatic lymph nodes was performed, but pathological assessment was negative for malignancy; (III) there was no previous pathological confirmation. Medical records were reviewed to obtain information regarding patient characteristics, lesion size and location, biliary stent prior to EUS, surgery performed, EUS results, clinical outcomes, and pathology. Informed consent was obtained before the EUS-FNA procedures. All procedures performed in this study involving human participants were in accordance with the Declaration of Helsinki (as revised in 2013).

\section{EUS-FNA procedures}

EUS was performed using a convex linear-array endoscope (EG-580UT or 530UT: Fujifilm Corp, Tokyo, Japan) connected to an ultrasound device (SU-9000 or SU8000 ultrasound processor; Fujifilm Corp). Before EUSFNA, a systematic scan of the pancreatobiliary system was conducted. The location of the mass was defined as uncinate, head, neck, body, and tail. The maximum diameter of the mass was recorded as the size of the mass. EUS-FNA was performed with a $22 \mathrm{G}$ needle (EchoTip, Cook Medical, Bloomington, IN, USA). EUS-FNA was repeated until sufficient macroscopic sampling (tiny white filiform tissue) had been acquired.

All of adverse reaction was recorded if happened. Once perforation or uncontrolled bleeding happened and observed under scope during EUS-FNA procedure, the operation was ceased and turned for surgical intervention. All the patients were closely monitored for vital signs and fasting for 1 day after EUS-FNA, fluid infusion treatment was supplied to the patients. Once patients showed with persistent fever, unstable blood pressure, or chest and abdominal pain, blood test and CT scan were applied to help judging whether happening of minor perforation, delayed bleeding, pancreatitis or infection.

\section{Pathological evaluation}

All the aspirated tissue was directly embedded in gel and sent for paraffin fixation. Slices were subjected to hematoxylin-eosin staining and immunohistochemical staining. The definitive pathological diagnosis was made by 2 pathologists. The final results were classified into positive (atypical cells or malignancy) or negative (no malignancy or being inadequate) according to the pathological diagnosis.

\section{Statistical analysis}

Normally distributed data were expressed as mean and standard deviation (SD), whereas non-normally distributed data were expressed as median and range.

\section{Results}

Patient characteristics, lesion features, and clinical outcomes are summarized in Table 1. A total of 11 patients were included in this study, among which 8 were males 
Table 1 Characteristics, lesion features, and clinical outcomes of the patients

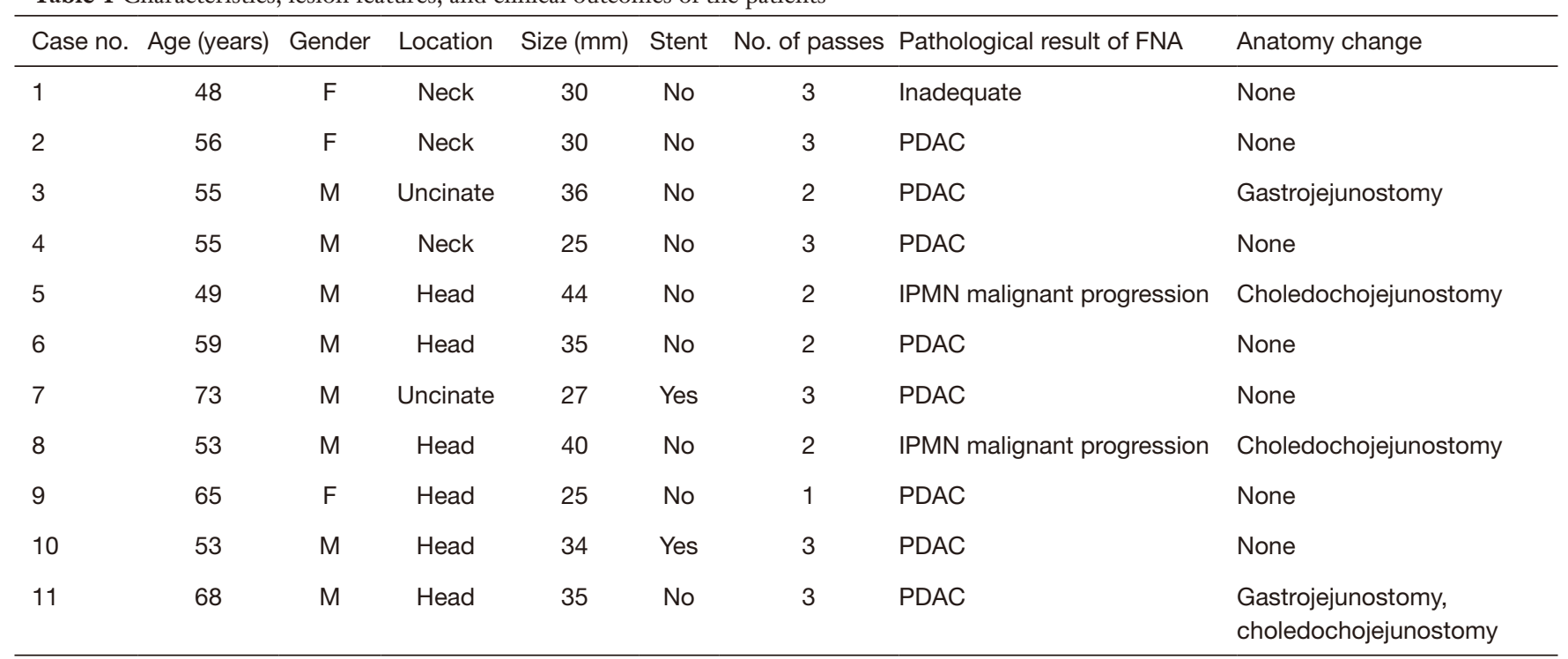

FNA, fine-needle aspiration; PDAC, pancreatic ductal adenocarcinoma; IPMN, intraductal papillary mucinous neoplasm.

and 3 were females. The median age of the patients was $57.6 \pm 7.55$ years (range, 48 to 73 years). The technical success rate of EUS-FNA was $100 \%(11 / 11)$. Eleven lesions were detected at the pancreas neck $(n=3)$, head $(\mathrm{n}=6)$, and uncinate process $(\mathrm{n}=3)$. The average lesion size was $35 \pm 3.16 \mathrm{~mm}$ (range, 25 to $44 \mathrm{~mm}$ ). The median number of needle passes was 3 (range, 1 to 3 ). Five patients suffered from biliary obstruction, among which 2 patients underwent percutaneous transhepatic cholangiodrainage (PTCD) before surgical exploration and switched to biliary stent implantation afterwards [1 endoscopic retrograde biliary drainage (ERBD), 1 self-expanding metal stent (SEMS) under PTCD], while the other 3 patients had choledochojejunostomy during surgery. Furthermore, prophylactic gastrojejunostomy was performed in 2 patients.

According to the pathological results, 10 (90.9\%, 10/11) samples were positive and 1 was negative (being inadequate). Of these 10 positive samples, 8 were pancreatic ductal adenocarcinoma and 2 were intraductal papillary mucinous neoplasm with malignant progression. No EUSFNA-related complications occurred.

\section{Discussion}

Pancreatic cancer is one of the most challenging tumors due to its delayed detection and poor prognosis. Surgical resection remains the most potentially curative intervention. Imaging has a crucial role in helping to stratify patients to stage-appropriate therapies. The characteristics used to define resectable, borderline resectable, and unresectable disease are based on the use of cross-sectional imaging. After ruling out distant metastasis, local resectability is mainly determined by the degree of circumferential involvement of regional arteries and veins surrounding the tumor and the narrowing of veins. The accuracy of evaluation for resectability of pancreatic cancer was shown to be $60-83 \%$ (5). In our study, all the ruled-in lesions (unresectable at surgery) were on the right side of the superior mesenteric vein (SMV) (neck, head, and uncinate process; Figure 1A). For the special anatomical characteristics of the pancreas, sometimes it is difficult to precisely predict the resectability, especially when the lesion is close to important vessels (6).

Intraoperative pancreas core biopsy is a suitable method for intrasurgical confirmation of pancreatic carcinoma. The level of sensitivity was shown to be $93.1 \%$, specificity was $99.1 \%$, the predictive value of positive results was $99.2 \%$, and the predictive value of negative results was $92.1 \%$ (7). For patients who fail to obtain a pathological diagnosis in surgical exploration (Figure 1B), how to obtain pathological confirmation before initiating chemoradiotherapy becomes crucial.

EUS-FNA plays an important role in pancreatic cancer management due to its ability to obtain pathological confirmation. The sensitivities and specificities of EUSFNA for the diagnosis of pancreatic cancer were 85-92\% and $96-98 \%$, respectively. EUS-FNA is helpful in N-staging 



Figure 1 EUS-FNA for a patient who failed to obtain a pathological diagnosis in surgical exploration. (A) A mass (blue circle) was found at the pancreas head under abdominal CT with contrast; (B) intraoperative pancreas core biopsy during surgical exploration revealed normal pancreas tissue (HE staining); (C) EUS-FNA. The mass was at the pancreas head (blue dotted circle). The plastic stent was observed under EUS: (D) tissues obtained by EUS-FNA diagnosed as pancreatic ductal adenocarcinoma (HE staining); (E) immunohistochemical staining for Ki-67; (F) immunohistochemical staining for p53. EUS-FNA, endoscopic ultrasound-guided fine-needle aspiration; CT, computed tomography.

and M-staging for its ability of pathological confirmation of lymph node metastasis, malignant ascites or liver metastases (8). For borderline resectable, unresectable, and metastatic stage patients, EUS-FNA is especially important for it can help to obtain a tissue diagnosis before initiating chemotherapy or radiation.

However, for the resectable pancreatic mass, whether to proceed with FNA before surgery remains a dilemma (9-12). The benefits and risks of FNA should be well balanced. In our hospital, based on the National Comprehensive Cancer Network Guidelines for Pancreatic Adenocarcinoma, pathological diagnosis is not mandatory before surgery for resectable cases if malignancy is highly suspected (13). It was reported that repeat EUS-FNA of pancreatic lesions is necessary in patients with a negative first EUS-FNA due to its improvement of the diagnostic yield $(14,15)$. Whether EUS-FNA plays the same role in patients who fail to obtain a pathological diagnosis in surgical exploration has not yet been reported. In our study, all the ruled-in patients achieved technical success in EUS-FNA. Ten patients (90.9\%) obtained pathological confirmation after EUS-FNA.
Obstructive jaundice is a common symptom complex in pancreatic cancer. In addition to choledochojejunostomy, it can also be managed by placement of a plastic or metal biliary stent. The biliary endoprosthesis, particularly SEMS, can cast an acoustic shadow and make EUS visualization of a pancreatic mass more difficult. Furthermore, the inflammatory reaction induced by a stent may have a negative impact on the diagnostic yield of FNA $(16,17)$. Bekkali et al. reported that SEMS use had a negative impact on tissue diagnosis in pancreatic head masses (18), while Ranney et al. reported that the presence or absence of a biliary stent, whether plastic or metal, does not have an impact on the diagnostic yield or technical difficulty of EUS-FNA (19). In our study, 2 patients underwent biliary stent implantation, in whom EUS-FNA was not affected and positive pathological diagnosis was achieved (Figure 1C-1F).

Surgically altered anatomy sometimes limits EUS imaging. In our study, 2 patients underwent choledochojejunostomy to relieve jaundice, 1 patient underwent prophylactic gastrojejunostomy to prevent digestive tract obstruction caused by subsequent tumor progression, and 1 patient 
underwent both choledochojejunostomy and prophylactic gastrojejunostomy. In these situations, the surgical anatomy did not significantly alter the standard endoscopic relationship or the orientation to the extraluminal organs. As a result, the standard imaging planes were not affected, and EUS-FNA was successful (20).

Intraoperative biopsy is the first choice diagnostic modality for unresectable pancreatic neoplasms at surgery, while our experience suggests that for patients who fail to obtain a pathological diagnosis in surgical exploration, EUS-FNA is still worth an attempt. However, this study had several limitations. First, this was a cohort with a limited sample size. Second, all the patients were selected in a single tertiary hospital retrospectively. Thus, further multi-center large-scale prospective studies are required to fully evaluate the efficacy and safety.

\section{Acknowledgments}

Funding: The study was supported by grants from Shanghai Municipal Science and Technology Committee (No. 19ZR1409600), Research and Development Fund of Zhongshan Hospital Affiliated to Fudan University (No. 2019ZSFZ28), and Clinical Research Fund of Zhongshan Hospital Affiliated to Fudan University (No. 2020ZXLC33).

\section{Footnote}

Reporting Checklist: The authors have completed the STROBE reporting checklist. Available at https:// gs.amegroups.com/article/view/10.21037/gs-21-913/rc

Data Sharing Statement: Available at https://gs.amegroups. com/article/view/10.21037/gs-21-913/dss

Conflicts of Interest: All authors have completed the ICMJE uniform disclosure form (available at https://gs.amegroups. com/article/view/10.21037/gs-21-913/coif). The authors have no conflicts of interest to declare.

Etbical Statement: The authors are accountable for all aspects of the work in ensuring that questions related to the accuracy or integrity of any part of the work are appropriately investigated and resolved. All procedures performed in this study involving human participants were in accordance with the Declaration of Helsinki (as revised in 2013). The study was approved by institutional ethics board of Zhongshan Hospital (No. B2021-213R) and informed consent was taken from all the patients.

Open Access Statement: This is an Open Access article distributed in accordance with the Creative Commons Attribution-NonCommercial-NoDerivs 4.0 International License (CC BY-NC-ND 4.0), which permits the noncommercial replication and distribution of the article with the strict proviso that no changes or edits are made and the original work is properly cited (including links to both the formal publication through the relevant DOI and the license). See: https://creativecommons.org/licenses/by-nc-nd/4.0/.

\section{References}

1. Ilic M, Ilic I. Epidemiology of pancreatic cancer. World J Gastroenterol 2016;22:9694-705.

2. White RR, Lowy AM. Clinical Management: Resectable Disease. Cancer J 2017;23:343-9.

3. Søreide O, Skaarland E, Pedersen OM, et al. Fine-needle biopsy of the pancreas: results of 204 routinely performed biopsies in 190 patients. World J Surg 1985;9:960-5.

4. Moossa AR, Altorki N. Pancreatic biopsy. Surg Clin North Am 1983;63:1205-14.

5. Dewitt J, Devereaux BM, Lehman GA, et al. Comparison of endoscopic ultrasound and computed tomography for the preoperative evaluation of pancreatic cancer: a systematic review. Clin Gastroenterol Hepatol 2006;4:71725; quiz 664.

6. Tamm EP, Balachandran A, Bhosale PR, et al. Imaging of pancreatic adenocarcinoma: update on staging/ resectability. Radiol Clin North Am 2012;50:407-28.

7. Schramm H, Urban H, Arnold F, et al. Intrasurgical pancreas cytology. Pancreas 2002;24:210-4.

8. Kitano $M$, Yoshida T, Itonaga $M$, et al. Impact of endoscopic ultrasonography on diagnosis of pancreatic cancer. J Gastroenterol 2019;54:19-32.

9. Asbun HJ, Conlon K, Fernandez-Cruz L, et al. When to perform a pancreatoduodenectomy in the absence of positive histology? A consensus statement by the International Study Group of Pancreatic Surgery. Surgery 2014;155:887-92.

10. Dietrich CF. The resectable pancreatic ductal adenocarcinoma: To FNA or not to FNA? A diagnostic dilemma, introduction. Endosc Ultrasound 2017;6:S69-70.

11. Petrone MC, Archibugi L. The resectable pancreatic ductal adenocarcinoma: To FNA or not to FNA? A 
diagnostic dilemma, FNA pros. Endosc Ultrasound 2017;6:S71-3.

12. Sahai AV. The resectable pancreatic lesion: To FNA or not to FNA? A diagnostic dilemma, FNA cons. Endosc Ultrasound 2017;6:S74-5.

13. Tempero MA, Malafa MP, Al-Hawary M, et al. Pancreatic Adenocarcinoma, Version 2.2017, NCCN Clinical Practice Guidelines in Oncology. J Natl Compr Canc Netw 2017;15:1028-61.

14. Mitchell RA, Stanger D, Shuster C, et al. Repeat Endoscopic Ultrasound-Guided Fine-Needle Aspiration in Patients with Suspected Pancreatic Cancer: Diagnostic Yield and Associated Change in Access to Appropriate Care. Can J Gastroenterol Hepatol 2016;2016:7678403.

15. Téllez-Ávila FI, Martínez-Lozano JA, Rosales-Salinas A, et al. Repeat endoscopic ultrasound fine needle aspiration after a first negative procedure is useful in pancreatic lesions. Endosc Ultrasound 2016;5:258-62.

16. Antonini F, Fuccio L, Giorgini S, et al. Biliary plastic stent does not influence the accuracy of endoscopic ultrasound-

Cite this article as: He MJ, Chen TY, Liu XY, Xu XY, Zhou $\mathrm{PH}$, Zhang YQ. Utility of endoscopic ultrasound-guided fineneedle aspiration in pancreatic cancer patients who failed to obtain a pathological diagnosis in surgical exploration. Gland Surg 2022;11(2):426-431. doi: 10.21037/gs-21-913 guided sampling of pancreatic head masses performed with core biopsy needles. Dig Liver Dis 2017;49:898-902.

17. Fisher JM, Gordon SR, Gardner TB. The impact of prior biliary stenting on the accuracy and complication rate of endoscopic ultrasound fine-needle aspiration for diagnosing pancreatic adenocarcinoma. Pancreas 2011;40:21-4.

18. Bekkali NLH, Nayar MK, Leeds JS, et al. Impact of metal and plastic stents on endoscopic ultrasound-guided aspiration cytology and core histology of head of pancreas masses. Endoscopy 2019;51:1044-50.

19. Ranney N, Phadnis M, Trevino J, et al. Impact of biliary stents on EUS-guided FNA of pancreatic mass lesions. Gastrointest Endosc 2012;76:76-83.

20. Wilson JA, Hoffman B, Hawes RH, et al. EUS in patients with surgically altered upper GI anatomy. Gastrointest Endosc 2010;72:947-53.

(English Language Editor: C. Betlazar-Maseh) 